\title{
Properties of Reinforced Concrete Beams Admixed with Polythene Fibre Polymer
}

\author{
U. Hassan ${ }^{1}$ and I. Abubakar ${ }^{2}$ \\ ${ }^{I}$ Dantata and Sawoe, Nigeria Limited, Kano. Nigeria \\ ${ }^{2}$ Departments of Civil Engineering, Ahmadu Bello University, Zaria, Nigeria
}

*Corresponding Author: U. Hassan, Departments of Civil Engineering, Ahmadu Bello University, Zaria, Nigeria

\begin{abstract}
Now a day we are facing environment protection problems. Many things which are invented for our luxurious life are responsible for polluting environment due to improper waste management technique. One of them is the polythene (Nylon) bags and sachets which have to be disposed or recycled properly to maintain the beauty of our nature. To address this issue the fibres from used polythene bags and sachets were added in various percentages in the M20 grade concrete. This study thus examines the influence of addition of polythene fibre into concrete at a dosage of $0.1 \%$ to $0.75 \%$ of total weight of concrete as an additional material in the concrete. The Polythene fibre were cut manually into a rectangular strips of 10mm widths and $50 \mathrm{~mm}$ lengths which was added to concrete grade 20 mixed in accordance with CNR DT-204/2006, in Euro code of practice. Tests were carried out as recommended by various recommended codes to determine the properties and suitability of the constituent materials such as aggregates, cement and steel in the mix. From the experiment it was found that at $0.30 \%$ inclusion of the polythene fibre, the design strength of the concrete grade 20N/mm2 at 28days was still achievable with a slight decreased in the weight of the concrete cube. More so the flexural or load strength of the concrete at 28 days casting increased marginally from $130 \mathrm{~N} / \mathrm{mm} 2$ $(0.00 \%$ fibre) to $133.87 \mathrm{~N} / \mathrm{mm} 2(0.40 \%$ fibre). The flexural strength at this value was observed to increase by about $3.00 \%$. This implies that the optimum fibre content for the flexural strength of the prism was $0.4 \%$. The study also shows that the modulus of elasticity of the concrete prism increased from $21173.32 \mathrm{~N} / \mathrm{mm} 2(0.00 \%$ fibre) to $21438.14 \mathrm{~N} / \mathrm{mm} 2(0.40 \%$ fibre).This also gives an increase in the modulus of elasticity of about $4.00 \%$. Thus implies that the optimum fibre content for the modulus of elasticity was $0.40 \%$.
\end{abstract}

Keywords: Reinforced Concrete; Beams Properties; Admixed Polythene; Fibre polymer

\section{INTRODUCTION}

Concrete is a heterogeneous composite material made up of cement, fine and coarse aggregate and water mixed in desired proportion based on strength requirements [1]. Plain concrete does not withstand as much tensile forces as compared to compression. This main drawback has necessitated engineers to make use of conventional steel reinforcement to increase the tensile strength and ductility of concrete members [2]. The use of fibre in concrete will not only act as crack prevention but also substantially improve the tensile strength, cracking resistance, impact strength, wear and tear, fatigue resistance and ductility of the concrete. The concept of using fibre in concrete as reinforcement is not new.

In the early 1960's, only straight steel fibre were used and the major improvement in the area of ductility and fracture toughness as well as the flexural strength of the concrete was also reported [3]. More so, it is said that tensile strength of concrete is approximately one tenth of its compressive strength [4]. As a result for these characteristics, plain concrete members could not support loads and tensile stresses that occurred on concrete beams and slabs. This leads to the reinforcements of concrete with continuously reinforcing bars to withstand tensile stresses and compensate for the lack of ductility. The introduction of fibre is generally taken as a solution to develop concrete in view of enhancing its flexural and tensile strength [5]. Polythene fibre reinforcement not only improves the toughness of the material, the impact and the fatigue resistance of concrete, but it also increases the material resistance to cracking and, hence to water and chloride ingress with significant improvement in durability of concrete structure [6]. The use of fibre is gaining more prominence in the construction 
industry. It is said to be substituting and/or replacing conventional types of reinforcements in a variety of structures [7]. The class of fibre such as the polythene fibre has been classified as structural or macro synthetic fibre have been noted to have appealing characteristics, hence a gradual shift towards its use as a reinforcement material for concrete [7]. This class of fibre has also been reported to have being of better economy when compared to other fibre such as glass fibre, does not deteriorate with age and it shows a better resistance to aggressive chemicals such as alkali [8].

According to estimates, by the state agency responsible for waste management in Kano metropolis, the city generates currently approximately 3,085 tons of solid waste per day. Analysis of the waste type shows that Kano metropolis's solid waste consists to a large extent of organic and other biodegradable matter (43\%) in which polythene (Nylon) from industries used in residential house hold constitute about half of this percentages [9]. Due to the large number of this polythene (Nylon) waste factories coupled with the high demand of their products in Kano metropolis, the disposal of the used polythene waste is creating a serious environmental issue in the state. It is then necessary to examine the best way to combat the waste disposal problem created by the use of the polythene leather as well as attaching economic value to the waste. It is on the forego discussion that this paper is aimed at examine;

i) The material properties of elements such as coarse and fine aggregate, cement, steel water and polythene fibre in a reinforced concrete beam.

ii) Examining the effect of polythene fibre as admixtures in the compressive, shear and deflection of a reinforced concrete beam.

\section{Materials AND Methods}

\subsection{Materials}

The materials used in the experiment include, cement, coarse aggregate, fine aggregate, water, steel and polythene (Nylon) fibre. The polythene fibre was obtained directly from the manufacturer that provided most of its properties. Tests on the constituentmaterials that make up the mix were conducted and are as outlined below. The objective of these tests was to ascertain that the properties of the materials conform to acceptable requirements and standard.

\subsubsection{Coarse Aggregate (Flakiness and Elongation Test)}

The Coarse aggregate used for the experiment, comprised of crushed granite obtained from Dantata and Sawoe quarry plant along Hadejah road in Kano state, North West Nigeria.The flakiness and elongation index were determined by the method described in[10].

Tables 1 gives the results obtained for the flakiness index while Table 2 gives the results of the elongation index for the coarse aggregate in the experiment.

Flakiness index test on coarse Aggregates was given by;

Flakiness index $=\frac{\mathrm{A}}{\mathrm{A}+\mathrm{B}} \mathrm{X} 100 \%$

Where A equalsWeight passing a given slot;

$B$ equals Weight retained on the same slot.

From Table 1, the Flakiness index was computed as;

Flaxiness Index $=\frac{38.65}{38.65+161.32}=19.3 \%=19.0 \%$

Table1. Results for Flakiness index test on coarse Aggregates (Mass of aggregates = 200grms)

\begin{tabular}{|c|c|c|c|c|}
\hline Sieve Sizes $(\mathrm{mm})$ & (A) & $=$ Weight Passing $(\mathrm{g})$ & (B) & $=$ Weight Retained $(\mathrm{g})$ \\
\hline 50.00 & & - & & - \\
\hline 38.10 & & - & & - \\
\hline 25.40 & & 7.72 & & 25.74 \\
\hline 19.05 & & 2.36 & & 45.88 \\
\hline 12.70 & & 16.47 & & 42.00 \\
\hline 9.52 & & 12.10 & & 47.70 \\
\hline
\end{tabular}




$$
\sum=38.65 \mathrm{~g} \quad \sum=161.42 \mathrm{~g}
$$

The Elongation index obtained from the expression;

Elongation index $=\frac{\sum \mathrm{M}_{2}}{\sum \mathrm{M}_{1}} \mathrm{X} 100 \%$

Where $\sum \mathrm{M}_{2}$ equals sum of the masses of size fractions not passing the gauge, in grams,

$\sum \mathrm{M}_{1}$ equals sum of the masses of size fractions in grams.

From Table 2, the elongation index is computed as;

Elongation index $=38.65 / 161.42$ X $100=23.94 \%=24 \%$

Table2. Results for Elongation Index Test on coarse Aggregate (Mass of aggregate = 200grms)

\begin{tabular}{|c|c|c|}
\hline Sieve Sizes $(\mathrm{mm})$ & $\left(\mathrm{M}_{2}\right)=$ Weight Passing $(\mathrm{g})$ & $\left(\mathrm{M}_{1}\right)=$ Weight Retained $(\mathrm{g})$ \\
\hline 50.00 & - & - \\
\hline 38.10 & - & - \\
\hline 25.40 & 7.72 & 45.74 \\
\hline 19.05 & 2.36 & 42.88 \\
\hline 12.70 & 16.47 & 47.70 \\
\hline 9.52 & 12.10 & $\sum=161.42 \mathrm{~g}$ \\
\hline
\end{tabular}

\subsubsection{Coarse Aggregate (Particle Size Distribution)}

Samples of coarse aggregate were prepared in accordance with procedures described in BS812-1984 and sieve analysis was carried out and as presented in Table 3.

Table3. Sieve Analysis of Coarse Aggregate

\begin{tabular}{|c|c|c|}
\hline BS Sieve (mm) & \% of Weight Retained & \% of passing \\
\hline 40 & 0 & 100 \\
\hline 20 & 16.26 & 83.74 \\
\hline 10 & 83.04 & 0.7 \\
\hline 4.75 & 0.7 & - \\
\hline 2.36 & - & - \\
\hline 1.18 & - & - \\
\hline $600 \mu$ & - & - \\
\hline $300 \mu$ & - & - \\
\hline $150 \mu$ & - & - \\
\hline
\end{tabular}

\subsubsection{Fine aggregate (particle size distribution)}

Fine aggregate used in this experiment consist of naturally occurring sand obtained from River Hadejah passing through Wudil in Kano State. The sieve analysis of the fine aggregate was carried out in accordance with[11] and is as shown in Table 4, while Fig 1 shows the grain size distribution curve, sand conforming to Zone II.

Table4. Sieve Analysis of Fine Aggregate

\begin{tabular}{|c|c|c|}
\hline BS Sieve $(\mathrm{mm})$ & \% of Weight Retained & \% of passing \\
\hline 10 & 0 & 100 \\
\hline 4.75 & 6.64 & 93.36 \\
\hline 2.36 & 12.61 & 80.75 \\
\hline 1.18 & 12.25 & 68.5 \\
\hline $600 \mu$ & 23.5 & 45.0 \\
\hline $300 \mu$ & 32.6 & 12.4 \\
\hline $150 \mu$ & 12.4 & 0 \\
\hline
\end{tabular}




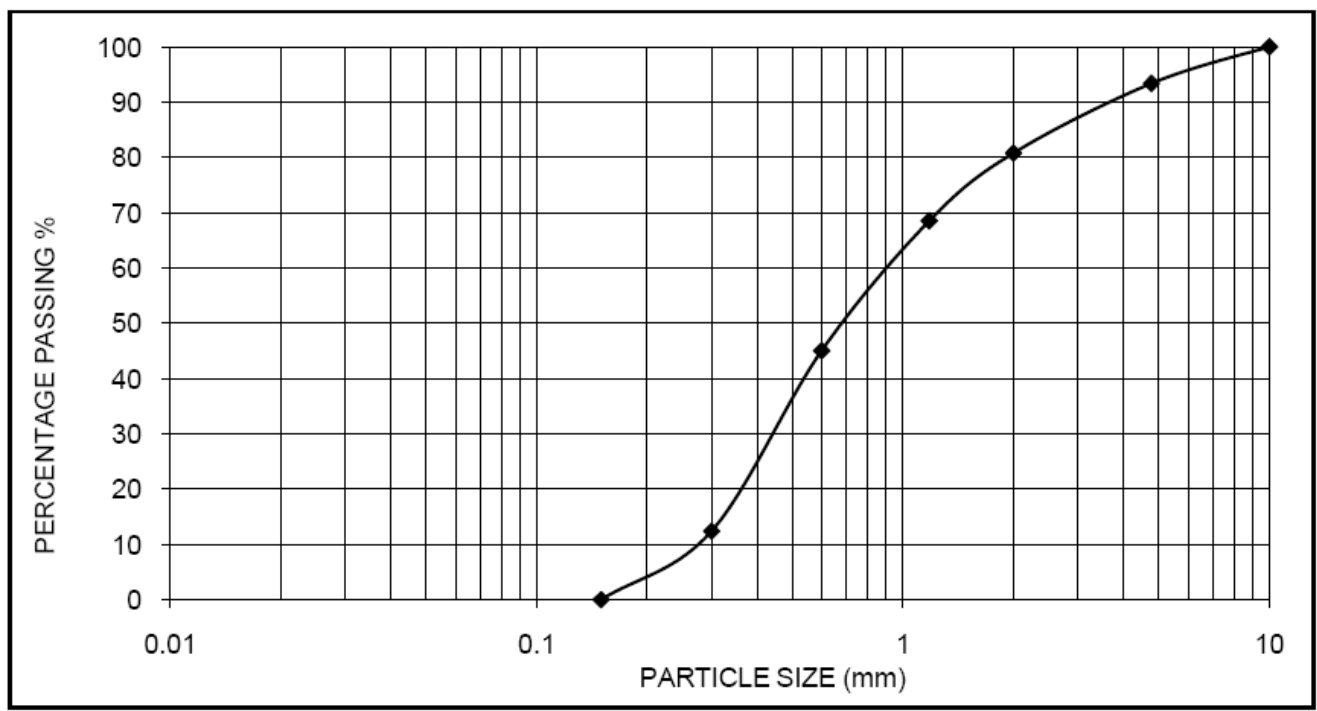

Fig1. Grain size distribution curve for fine aggregate

\subsubsection{Cement (Consistency, Setting Time and Soundness Tests)}

Ordinary Portland cement (Dangote Brand of grade 42.5) was selected for use in this experiment. Physical test was carried out on the Cement in accordance with IS 4031 Part 1- 4 (1988), test for cement.

\subsubsection{Procedures for the Determination of Cement Consistency}

This was determined in accordance with procedures given by[12].The procedures were outlined as following;

1. About $400 \mathrm{~g}$ of cement was measured and placed in an enameled tray.

2. About $25 \%$ of water by weight of dry cement was weighed and thoroughly mixed to get a cement paste. "Gauging time" for mixing was about 5 minutes.

3. The vicat mould, resting upon a glass plate was then filled with this cement paste.

4 The surface of the paste was then smoothen after filling the mould completely, thus making it level with top.

5. The whole assembly (i.e. moulds + cement paste + glass plate) was then placed under the rod bearing plunger.

6. The plunger was then gently lowered so as to touch the surface of the test block and the plunger was quickly released to allow it to sink into the paste.

7. The depth of penetration was then measured and recorded.

8. Several pastes with varying percentages of water content were prepared and average depth of penetration taken as;

$\mathrm{P}=\frac{\mathrm{W}}{\mathrm{C}} \times 100 \%$

Where; W equals quantity of water added, $\mathrm{C}$ equals quantity of cement used.The values in Table 5 gives the average values of test results obtained for the consistency test for the cement.

Table5. Consistency Test on Cement

\begin{tabular}{|c|c|}
\hline Sample Identification mark & Consistency \\
\hline A & 33 \\
\hline B & 33 \\
\hline C & 33 \\
\hline D & 33 \\
\hline
\end{tabular}

\subsubsection{Setting Time and Soundness Test for Cement}

Setting time of the cement was obtained using the (Le-chatelier methodas per[13]. 
Table 6 gives the values obtained for Setting time and Soundness of cement from the laboratory experiment. The results show that the mean initial / final Setting time and Soundness of the cement were obtained as 46.0 / 588.5 minutes and $0.45 \mathrm{~mm}$ respectively.

Table6. Results of setting time and soundness of cement

\begin{tabular}{|c|c|c|c|}
\hline $\begin{array}{c}\text { Sample identification } \\
\text { Marks }\end{array}$ & $\begin{array}{c}\text { Initial setting Time } \\
\text { (minutes) }\end{array}$ & $\begin{array}{c}\text { Final Setting Time } \\
\text { (minutes) }\end{array}$ & Soundness (mm) \\
\hline A & 45 & 588 & 0.3 \\
\hline B & 45 & 585 & 0.5 \\
\hline C & 46 & 591 & 0.5 \\
\hline D & 48 & 590 & 0.4 \\
\hline
\end{tabular}

Where A, B, C and D in the table are sample identification marks for the four test samples used.

\subsubsection{Cement (Fineness Test)}

The method used to determine fineness of cement was the dry Sieving Method as per[14]. The fineness of cement was measured by sieving it on standard sieves. The proportions of cement where the grain sizes are larger than the specified mesh size was then determined. Four separate samples of the cements were weighed, sieved and mass retained on the sieve was computed as a percentage of the total mass as given by the equation below;

Percentage of Residues $=\frac{\text { weight } \text { of Samples retained in the sie ve }}{\text { Total weight of samples }}$

Table 7 gives the values of fineness of cement obtained from the laboratory experiment. The mean value of fineness obtained was $4.0 \%$

Table7. Results for Fineness of Cement

\begin{tabular}{|c|c|c|}
\hline Weight of Sample (g) & Mass Retained (g) & Fineness (\%) \\
\hline 50 & 2.0 & 4.0 \\
\hline 60 & 2.5 & 4.0 \\
\hline 70 & 3 & 4.0 \\
\hline 80 & 3.2 & 4.0 \\
\hline \multicolumn{2}{|c|}{ Fineness Value $=$} & $\mathbf{4 . 0}$ \\
\hline
\end{tabular}

\subsubsection{Steel}

The steel used as reinforcements for beams are four- number high yield steels of diameter $12 \mathrm{~mm}$ and links $6 \mathrm{~mm}$ placed at $200 \mathrm{~mm}$ spacing. The link bars of diameter $6 \mathrm{~mm}$ was taken as nominal. The mean characteristic strength of the steels (main bars, diameter $12 \mathrm{~mm}$ ) was obtained to be $422 \mathrm{~N} / \mathrm{mm}^{2}$ while the mean elongation was $14.10 \%$. Table 8 give the mechanical properties of the steel.

Table8. Mechanical properties of steel used.

\begin{tabular}{|c|c|c|c|c|c|c|}
\hline S/NO & $\begin{array}{c}\text { Identification } \\
\text { No. }\end{array}$ & $\begin{array}{c}\text { Nominal } \\
\text { Diameter } \\
\text { measured } \\
(\mathrm{mm})\end{array}$ & $\begin{array}{c}\text { Cross } \\
\text { sectional } \\
\text { Area }\left(\mathrm{mm}^{2}\right)\end{array}$ & $\begin{array}{c}\text { yield Stress } \\
\left(\mathrm{N} / \mathrm{mm}^{2}\right)\end{array}$ & $\begin{array}{c}\text { Ultimate } \\
\text { Stress } \\
\left(\mathrm{N} / \mathrm{mm}^{2}\right)\end{array}$ & $\%$ Elongation \\
\hline 01 & JPF/Y12001 & 11.90 & 111.22 & 431.60 & 714.80 & 14.50 \\
\hline 02 & JPF/Y12002 & 10.80 & 91.61 & 431.60 & 719.30 & 13.90 \\
\hline 03 & JPF/Y12003 & 10.80 & 91.61 & 440.60 & 719.30 & 14.60 \\
\hline 04 & JPF/Y12004 & 10.80 & 91.61 & 386.60 & 629.40 & 13.70 \\
\hline & Mean Value & $\mathbf{1 1 . 0 7}$ & $\mathbf{1 0 0 . 2 6}$ & $\mathbf{4 2 2 . 6 0}$ & $\mathbf{6 9 5 . 7 0}$ & $\mathbf{1 4 . 2 0}$ \\
\hline
\end{tabular}

\section{Standard Requirements}
a) BS 8110 (1997) - Characteristic Strength $=$ FY $=460 \mathrm{~N} / \mathrm{mm}^{2}$
b) BS 4449 (1985) - Minimum Elongation = 14 percent
c) BS 8110 (1997) - Design Strength
i) Mild Steel $=218 \mathrm{~N} / \mathrm{mm}^{2}$
ii) High/ Tensile Steel $=410 \mathrm{~N} / \mathrm{mm}^{2}$ 


\subsubsection{Water}

Water used for mixing and curing concrete was clean, fresh water (tap water) which is good for drinking.

\subsubsection{Polythene Fibre}

The type of fibre polymer used in this research was the polythene (Nylon) with 'white master batch' as the raw materials. It was obtained directly from the production factory; Lela Agro Sack Company in Sharada phase III, Kano state. The Polythene fibre used was the type which the bond in the fibre is expected to be greatly increased compared to similar types with a smooth surface and a considerable pullout load [15]. Table 9 give the properties of the fibre.

Table9. Mechanical properties of Polythene fibre (Source; LELA Agro Sack Company Sharada Phase III, Kano)

\begin{tabular}{|l|l|}
\hline Thickness of the nylon fibre & $75 \mathrm{umm}-80 \mathrm{umm}$ \\
\hline Raw material of the fibre & Polyamine with white chips \\
\hline Temperature of melting & $186^{\circ} \mathrm{C}-196^{\circ} \mathrm{C}$ \\
\hline Tensile strength of the fibre & $950 \mathrm{MPa}-985 \mathrm{Mpa}$ \\
\hline Compressive strength of the fibre & Between $55-60 \mathrm{Mpa}$ \\
\hline Specific gravity & 1.14 \\
\hline Ultimate elongation & 20.0 \\
\hline
\end{tabular}

\subsubsection{Concrete Mix Design}

Mix design is the process of selection suitable ingredients of concrete and determining their proportions with aim of producing concrete of certain maximum strength and durability as economical as possible. The concrete mix in this research was designed as per[16].

The water/cement ratio used in the design was 0.50 with a mix proportion of ratio 1: $2: 4$ for a grade 20 concrete (generally accepted for structural concrete). Table 10 gives the mix design proportion of the constituent elements in the concrete.

Table10. Concrete mix proportion quantities per $M^{2}$ (Grade-20)

\begin{tabular}{|l|l|l|}
\hline S./ No & Materials & Quantity in $\mathrm{kg} / \mathrm{m}^{3}$ \\
\hline 1 & Cement & 290 \\
\hline 2 & Fine aggregate & 696 \\
\hline 3 & Coarse aggregate & 1429 \\
\hline 4 & Water & 145 \\
\hline 5 & $\begin{array}{l}\text { Polythene Fibre; } \\
0.1 \%-0.75 \%\end{array}$ & $2.56-19.20$ \\
\hline
\end{tabular}

\subsection{METHODS}

\subsubsection{Production of Concrete Cubes and Beams.}

\subsubsection{Mixing of Specimen}

Polythene fibres were cut into sizes $10 \mathrm{~mm}$ Wide X 50mm lengths in accordance with[17] as in plate I. The cuts polythene fibres were weighed on a weighing machine. Cement, fine aggregate, coarse aggregate and other ingredients in the concrete mix was also weighed accordingly and accurately as presented in Table 10. Hand mixing was adopted throughout the mixing process of the experimental work. The process of Production of Concrete Beams was presented in plate II. 15 Nos. of 150X150X150 mm concrete cubes for each percentage of fibre (A total of 105 Nos.) including control (without fibre inclusion) were prepared for the compressive strength test while about 9 Nos. of beams of size 150X150X750mm (A total of 63 Nos.) with nominal reinforcement (four numbers of $12 \mathrm{~mm}$ rods in both directions) was also cast for the flexural test. 5 Nos. of concrete cubes compressive strength was tested per day for each percentage of fibre after 7, 14, and 28 days curing while 3 Nos. of beams flexural strength was tested per day for each percentage of fibre after 7, 14, and 28 days curing. 


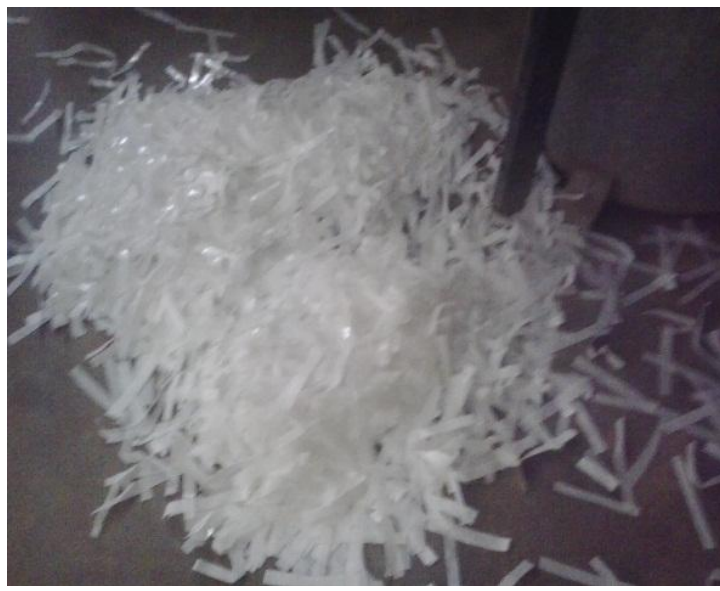

PlateI. Cut Polythene fibre (10mmX50mm)

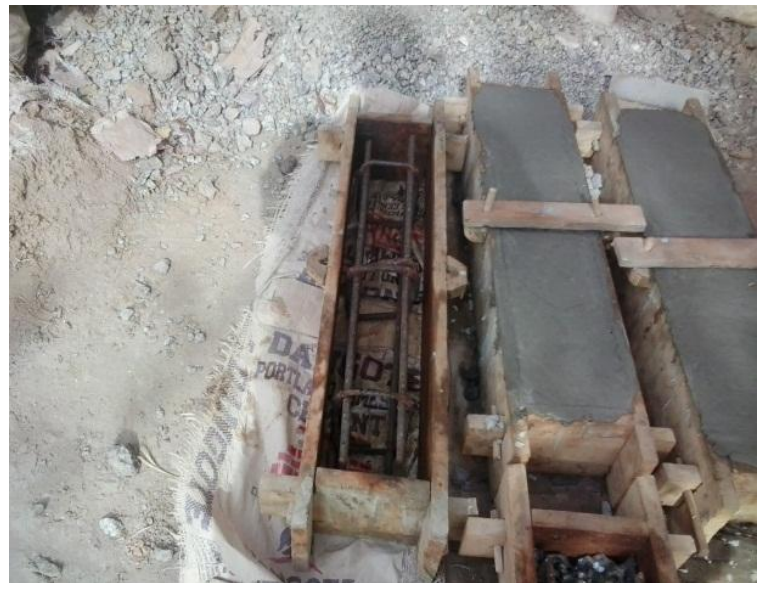

PlateII. Casting of concrete Beams

\subsection{Cube COMPRESSION TEST}

This test was conducted as per [18]. Cubes of standard size 150x150x150mm were used to find the compressive strength of the concrete. Specimens were placed on the bearing surface of the Avery Denison UTM, of capacity $2500 \mathrm{KN}$ without eccentricity and a uniform rate of loading of $550 \mathrm{Kg} / \mathrm{cm}^{2}$ per minute was applied till the failure of the cube. The maximum load was noted and the compressive strength was calculated using the equation;

$f_{c k}=P / A(M P a)$

Where, $f_{c k}$ equals Cube compressive strength, $\mathrm{P}$ equals cube compression load and $\mathrm{A}$, equals area of the cube on which load is applied; (equals $150 X 150=22500 \mathrm{~mm}^{2}$ )

\subsection{FleXURAL TeST}

Beams of size 150x150x750mm are tested using a flexure testing machine in accordance with [19], as presented in in plate III and Figure 2. The specimen was simply supported on the two rollers of the machine which are $600 \mathrm{~mm}$ apart, with a bearing of $50 \mathrm{~mm}$ from each support. Loads were applied on the beam from two rollers which are placed above the beam with a spacing of $200 \mathrm{~mm}$. As the load was been applied, the deformation of the beam was also noted. This reading was made possible by the help of dial gauge attached at the mid-point of the beam. The modulus of rupture was calculated using the formula.

$\sigma_{s}=p l / b d^{2}$

Where $\sigma_{s}$ equals modulus of rupture, $\mathrm{P}$ equals load in $\mathrm{N}$ applied to the specimen,l equals length in $\mathrm{mm}$ of the span on which the specimen is supported (600), b equals measured width in $\mathrm{mm}$ of the specimen and d equals measured depth in $\mathrm{mm}$ of the specimen at point of failure with the dial gauge attached at mid span of the testing beam.

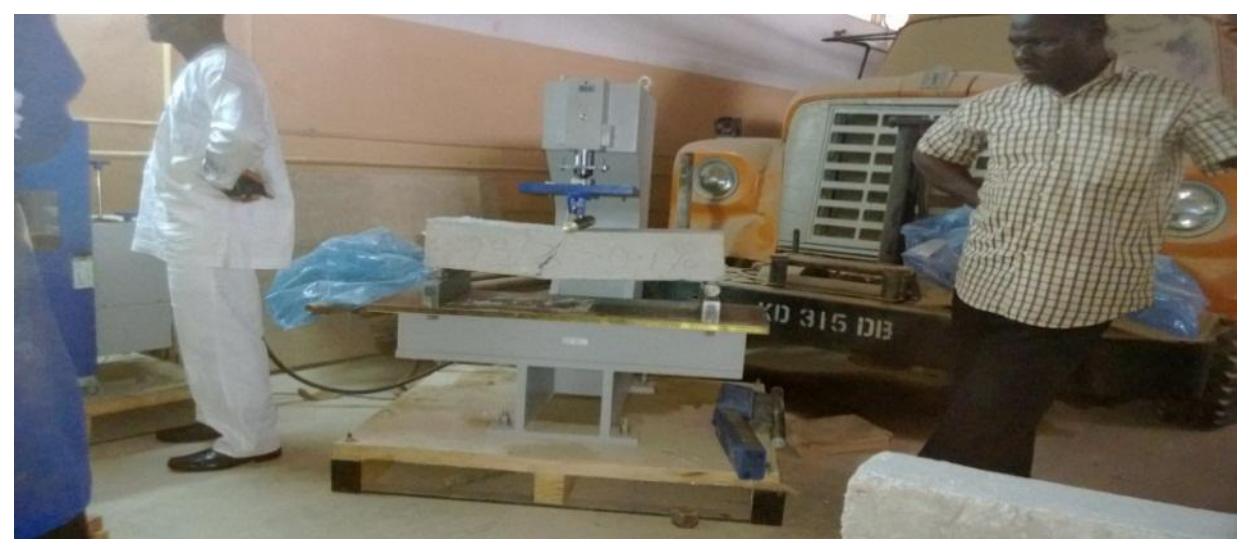

Plate III. Bending test on Beams [19] 


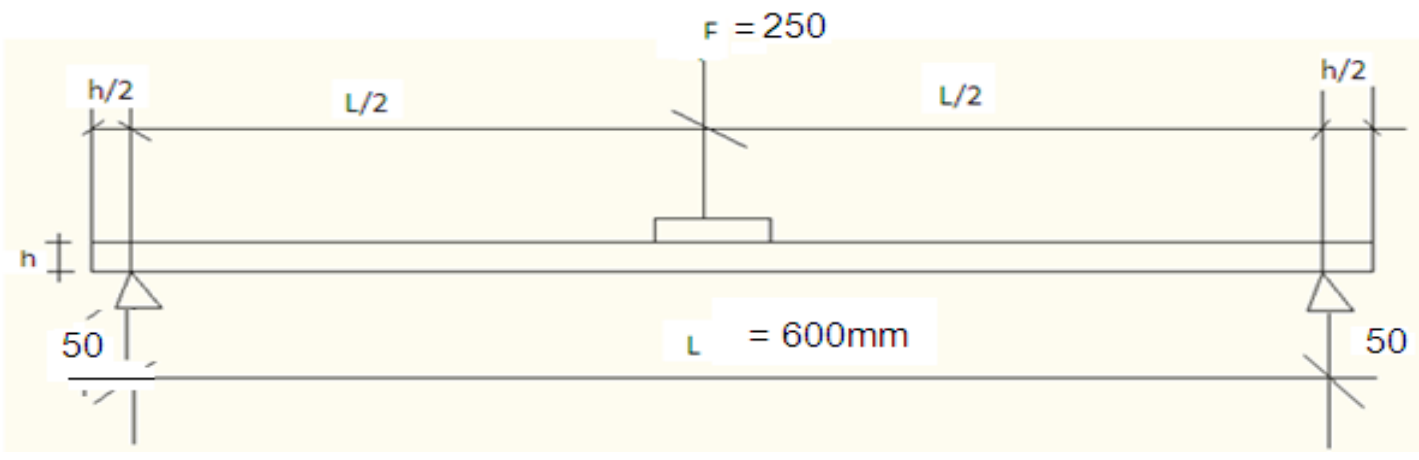

Fig2. Three-point Bending Test Set-up[19]

\subsection{Modulus OF Elasticity}

The Modulus of Elasticity (MOE) values were obtained using the known beam deflection equation as presented in equation 6 to 8 . Since the beam deflection values were obtained with the aid of the attached dial gauge, then, the MOE were easily computed. The Elastic Modulus was computed from the formula

$\delta=\frac{W L^{4}}{384 E I}$

and

$E=\frac{W L^{4}}{384 \delta I}$

where, E equals Modulus of Elasticity, $\delta$ equal deflection $(\mathrm{mm})$, W equals Failure Load/ Unit length of beam $(\mathrm{kN})$ and L equals Length of tested Beam $(\mathrm{mm})$, while I equals Beam Stiffness, express as;

$\left\{I=\frac{b h^{3}}{12}\right\}$

Where $b$ equals breadth of cast beam, while $h$ is the beam depth of the beam

\section{RESUltS AND DiscusSiONS}

\subsection{RESULTS}

The cubes compressive strength, beams prisms flexural strengths and modulus of elasticity values obtained from the laboratory experiments are as presented graphically in Figures 3 to 8 .

\subsubsection{Results of Cubes Compressive Strengths}

A graph of the cube compressive strength versus concrete age was presented in Figure 3 while that of the cube strength versus the percentage of fibre was presented in Figure 4.

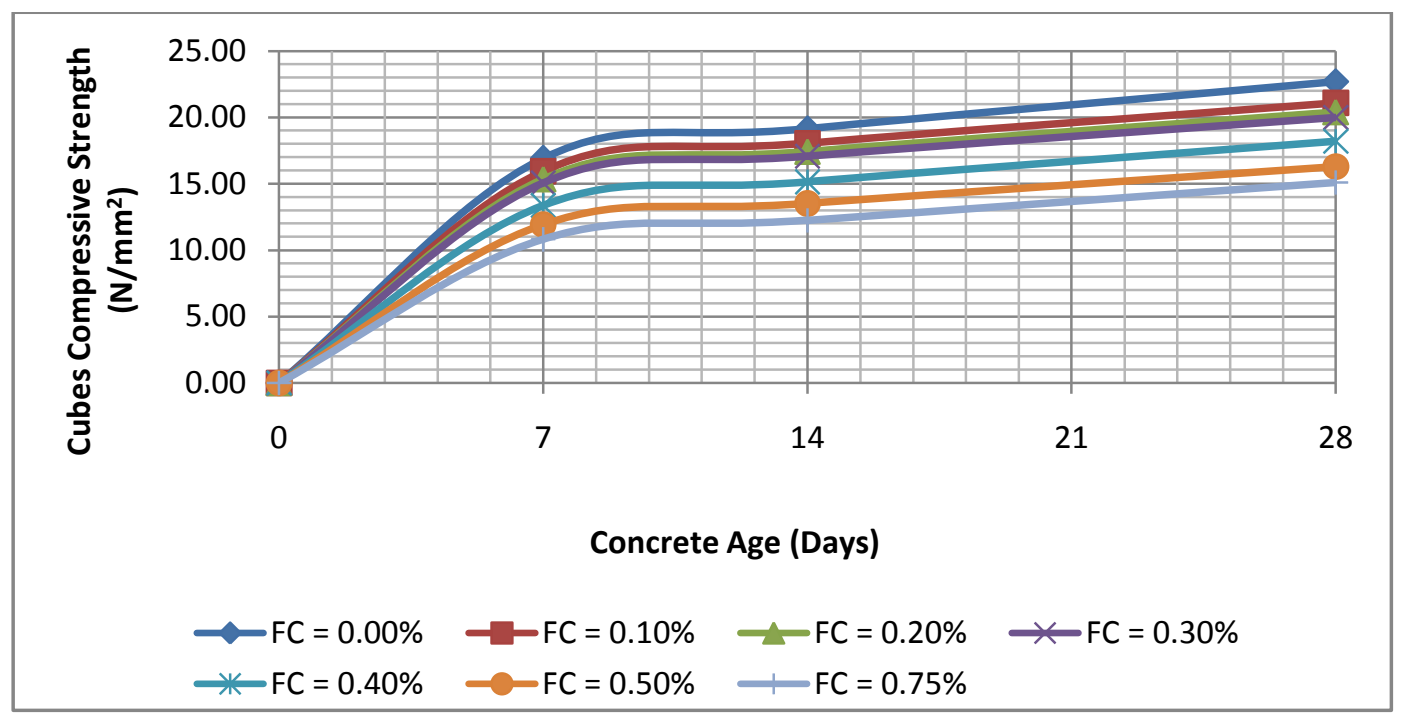

Fig3. Cubes Compressive Strength versus Concrete Age 
Figure 3 displayed the relationship between the polythene fibre modified concrete cubes and concrete age. It was observed from the Figure that the compressive strengths of the cubes increase with increasing age for all fibre content[20]. From the graph, it was cleared that the cube compressive strength increased linearly for 7 days, 14 days and 28 days[21].This linear increased may not be unconnected to an increased in the age of the concrete.

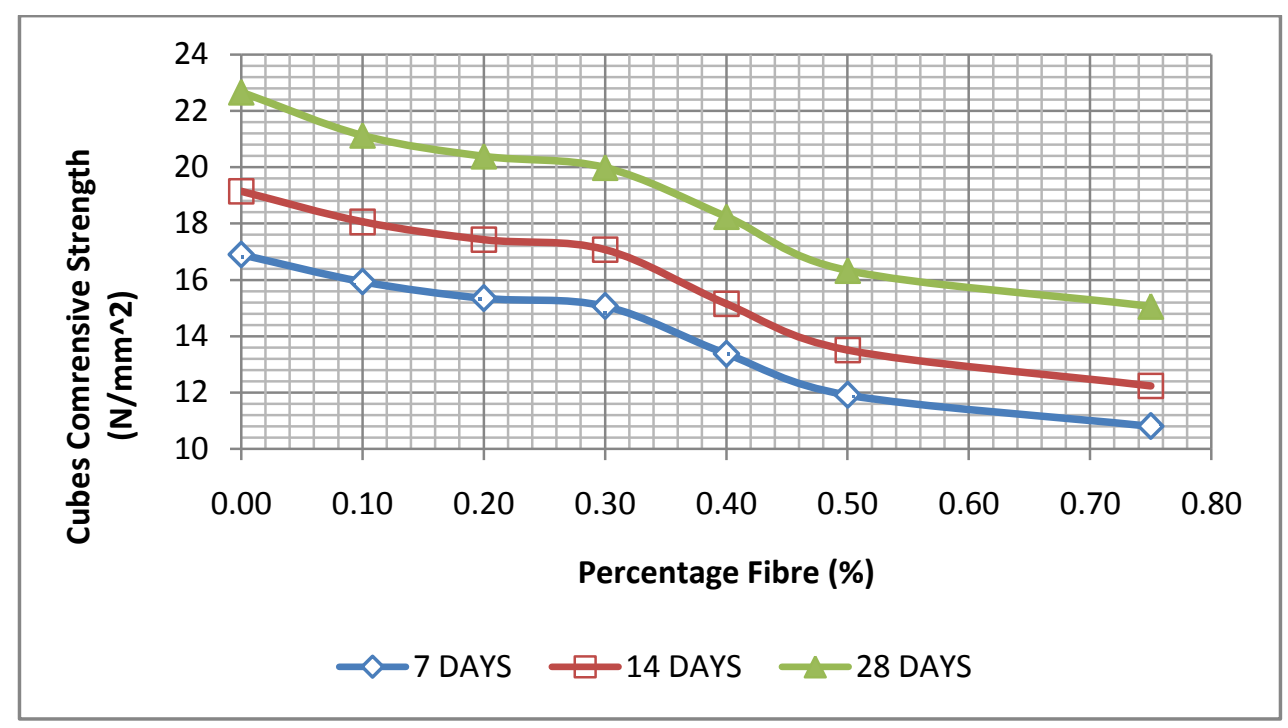

Fig4. Cubes Compressive Strength versus Percentage of Fibre

Figure 4 displayed the graph of cubes compressive strength of the concrete versus percentage of polythene fibre. The graph shows that fibre content lead to decrease in compressive strength of concrete; that is as the fibre concrete was increased from $0.00 \%$ (control) the compressive strength decreases. For instance at 28 days, the mean compressive strength for the control specimens was $22.70 \mathrm{~N} / \mathrm{mm}^{2}$. However, the compressive strength decreased to $21.10 \mathrm{~N} / \mathrm{mm}^{2}, 20.70 \mathrm{~N} / \mathrm{mm}^{2}$, $20.00 \mathrm{~N} / \mathrm{mm}^{2}, 18.70 \mathrm{~N} / \mathrm{mm}^{2}, 16.730 \mathrm{~N} / \mathrm{mm}^{2}$ and $15.10 \mathrm{~N} / \mathrm{mm}^{2}$ for fibre increments of $0.10 \%, 0.20 \%$, $0.30 \%, 0.40 \%, 0.50 \%$ and $0.75 \%$ respectively. This decrease can be attributed to an increase in the void ratio in the concrete caused by the presences of the polythene fibre which thus reduces the bulk density of the concrete cubes[22]. The design concrete mix used in the study is for target compressive strength of $20.0 \mathrm{~N} / \mathrm{mm}^{2}$. It is therefore clear that the target strength was still achievable for a fibre contents up to $0.1 \%, 0.2 \%$ and $0.3 \%$.This implies that the optimum value of the fibre content required for the compressive strength of the concrete is when the percentage of the fibre was at $0.3 \%$ of the total weight of the concrete.

\subsubsection{Results of load Strengths}

The plot of flexural strength versus concrete age at 7, 14 and 28 days is as shown in Figure 5

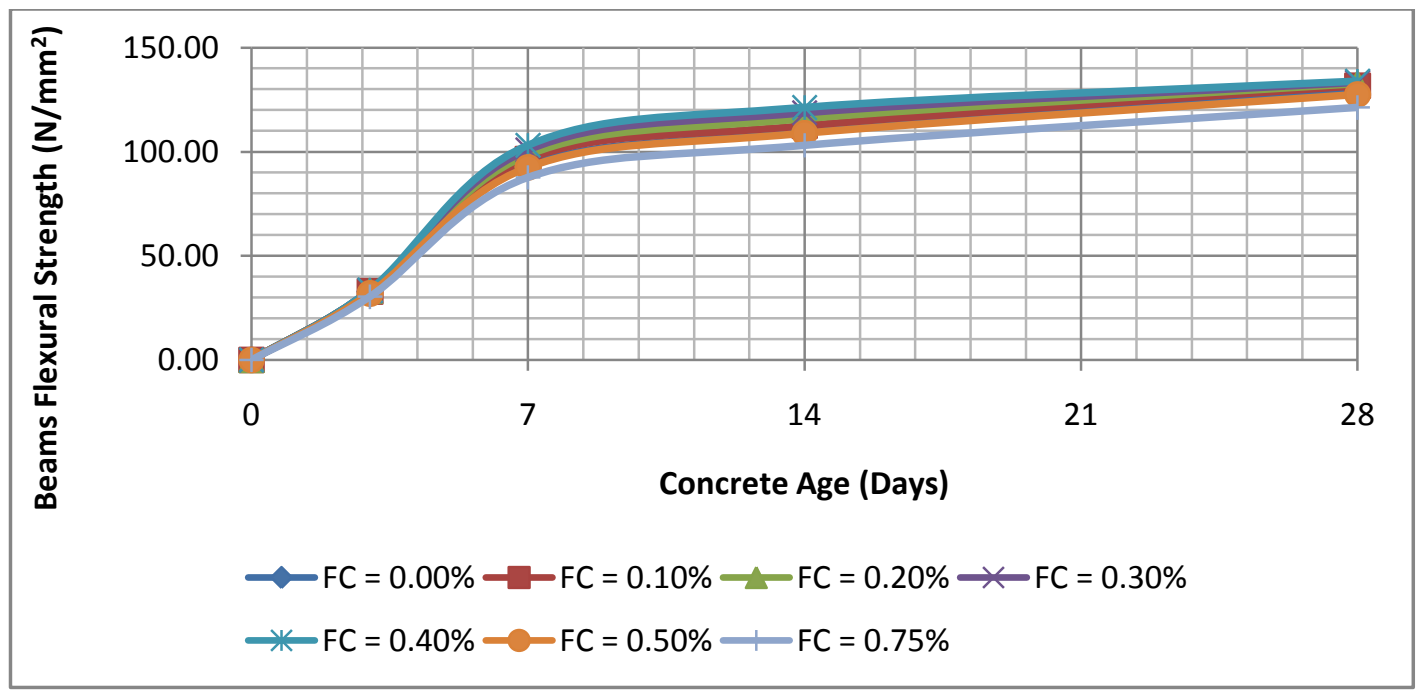

Fig5. Flexural Strength versus Concrete Age 
The relationship between flexural strength and concrete age was displayed in Figure 5 for various percentages of fibre in the concrete. It was cleared from the graph that as the age of curing of the beams increases for all percentages of fibres, the flexural strength also increases. This justifies the fact that at a proper curing, beam flexural strength increased with age in a parabolic curve [23].

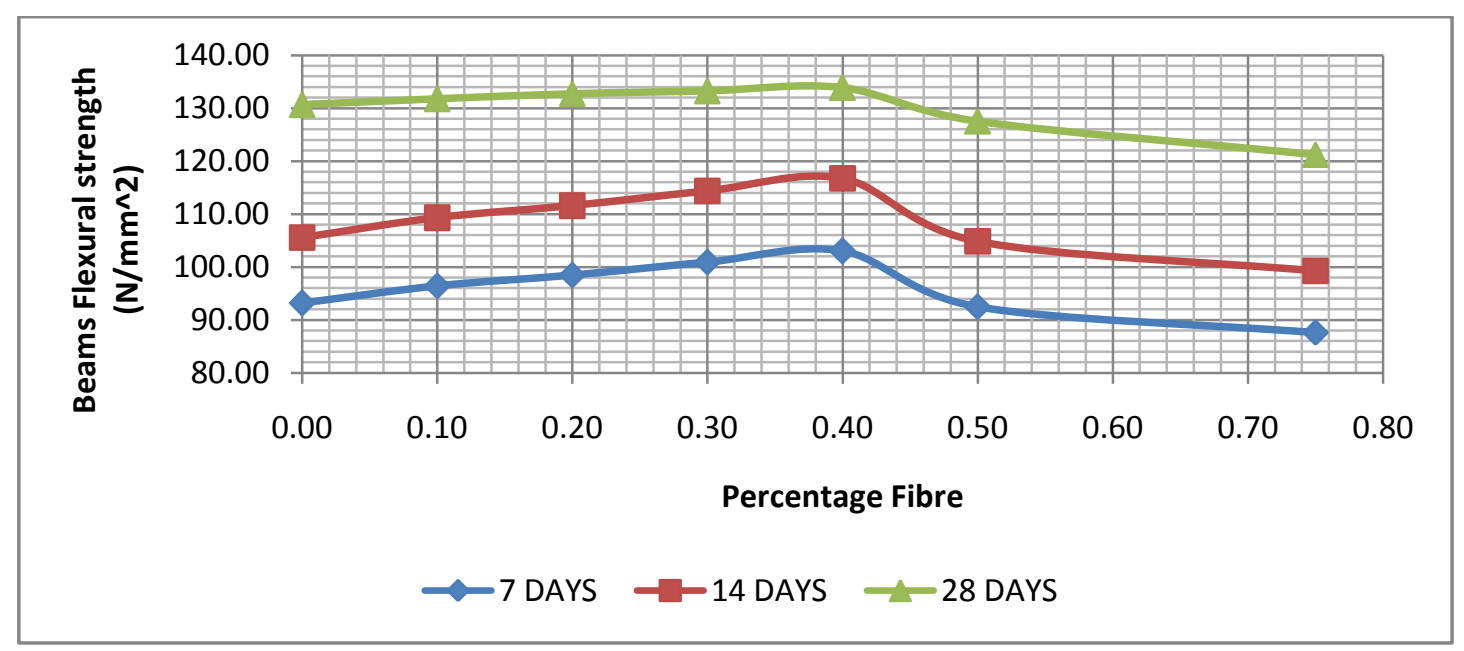

Fig6. Flexural Strength versus Percentage of Fibre

Figure 6 displayed the graph of flexural strength of the concrete prism versus percentage of polythene fibre. For all the three concrete ages under investigation, the flexural strength increased with increasing percentage fibre. This increase was as a result of total energy absorbed in breaking a specimen in flexure[23]. For instance, the values of the flexural strength at 28 days was observed to increase from $130.65 \mathrm{~N} / \mathrm{mm}^{2}, 135.75 \mathrm{~N} / \mathrm{mm}^{2}, 132.73 \mathrm{~N} / \mathrm{mm} 2,133.25 \mathrm{~N} / \mathrm{mm}^{2}$ and $133.87 \mathrm{~N} / \mathrm{mm}^{2}$ for $0.00 \%$ fibre (control beam), $0.10 \%$ fibre, $0.20 \%$ fibre, $0.30 \%$ fibre and $0.40 \%$ fibre respectively. At this maximum fibre content, $(0.40 \%)$, the load strength of the beam prism increased by about $3.0 \%$.

However, for fibre content beyond $0.40 \%$, the flexural strength of the beam was observed to decrease beyond the value obtained in the control beam. This sudden decrease in flexural strength may be connected to bond lost between aggregate particles and cement as a result of excessive polythene fibre content which then resulted to excess void in the concrete. Consequently, for protection of the beam against flexural failure, the fibre content must not exceed $0.4 \%$.

\subsubsection{Modulus of Elasticity}

Figure 7 show the graph of modulus of elasticity of the polythene fibre reinforced concrete beams versus the concrete age.

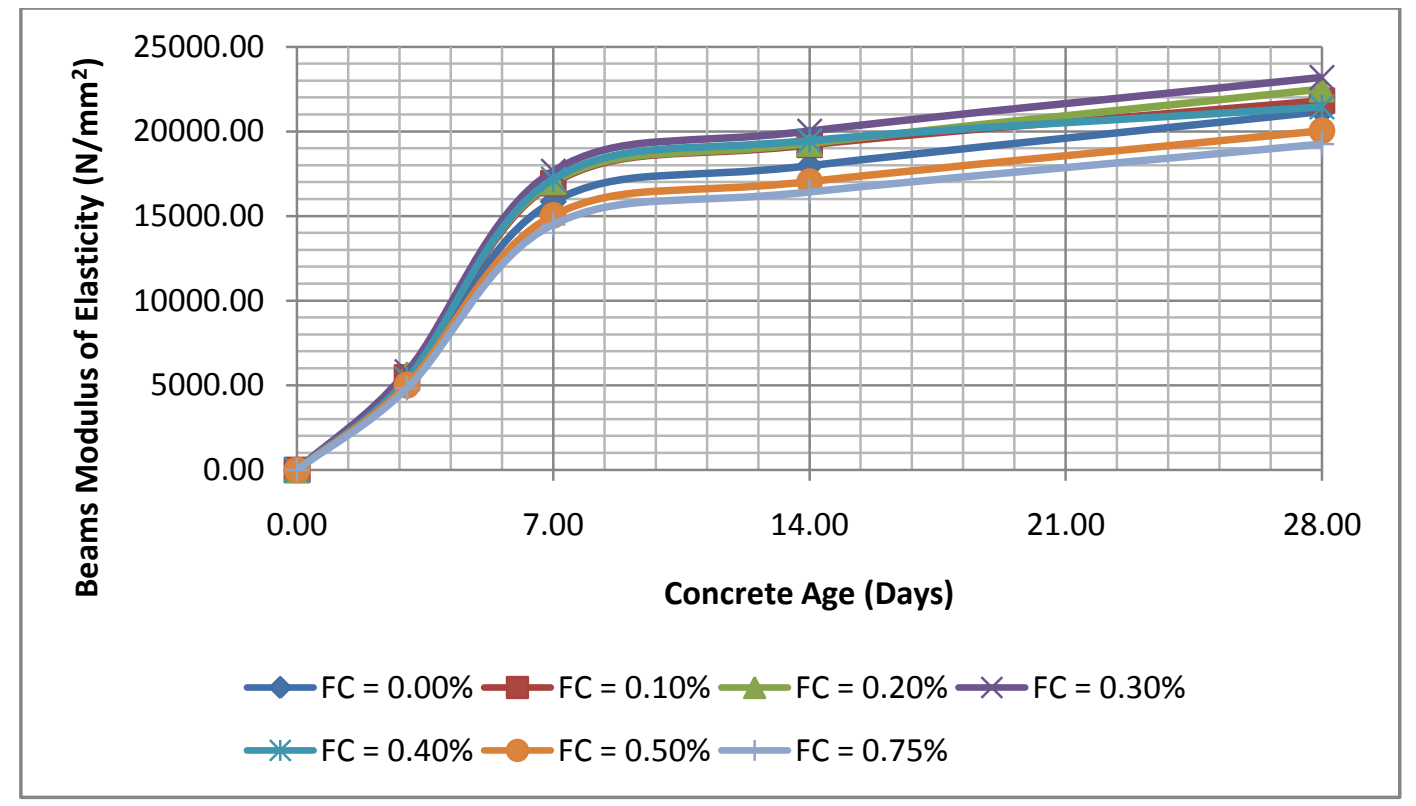

Fig7. Modulus of Elasticity versus Concrete Age 
The Figure shows that for all percentages fibre, the modulus of elasticity increases with increase age of concrete[24]. At each of the concrete ages of 7 days, 14 days and 28 days tested, the concrete modulus of elasticity increases linearly and it is seen that the concrete with $0.30 \%$ fibre having the highest value of modulus of elasticity irrespective of the age of the concrete. This also justifies that concrete strength increases with age at proper curing. The maximum increased at $0.3 \%$ fibre inclusion was a cleared indication that the optimum fibre content for maximum deflection of polythene fibre reinforced concrete beam under investigation was $0.30 \%$.

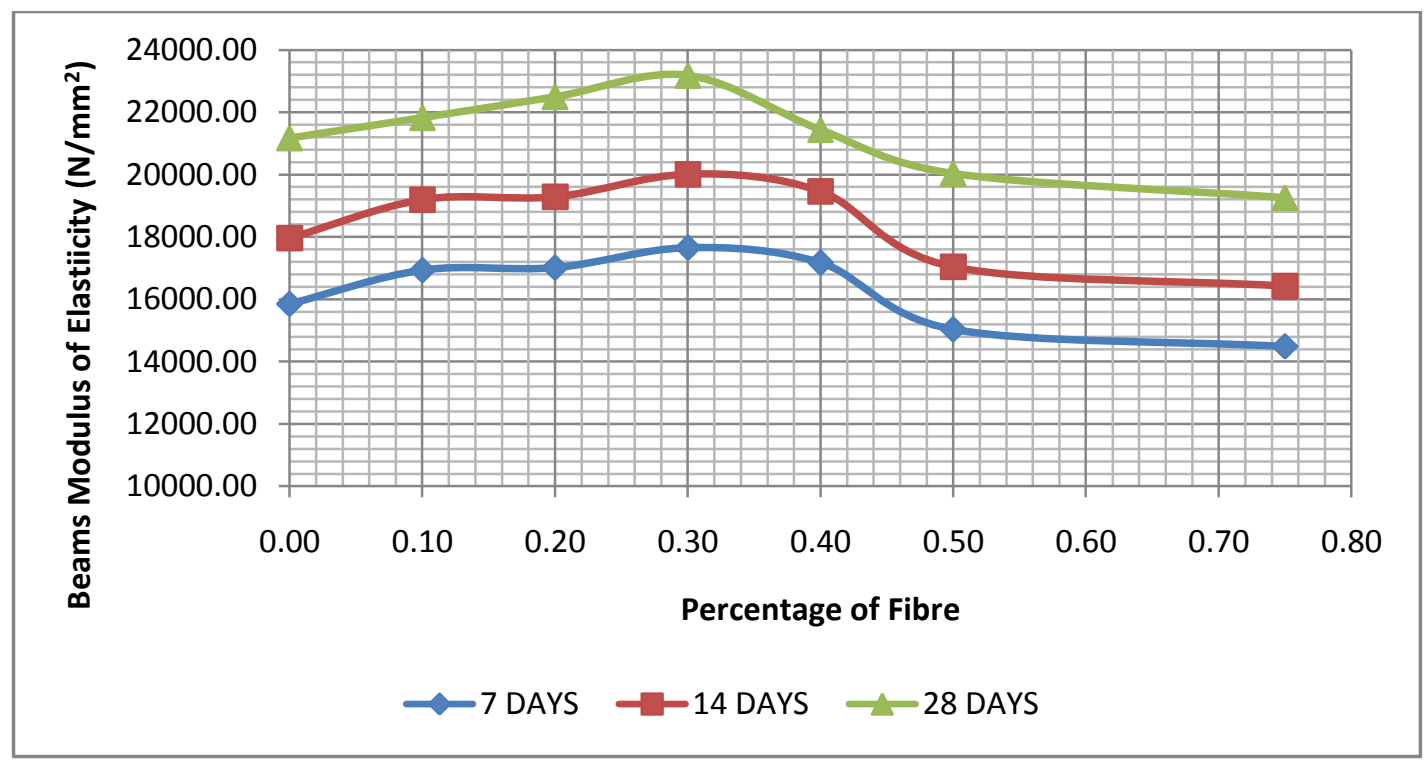

Fig8. Modulus of Elasticity versus Percentage of Fibre

Figure 8 displaced the plot of modulus of elasticity of the concrete prism against percentage of polythene fibre for all the three concrete ages. It was observed that modulus of elasticity increases with increasing percentage of fibre [25]. At 28 days, the modulus of elasticity of the concrete prism was $21173.32 \mathrm{~N} / \mathrm{mm}^{2}$ when the percentage fibre was $0.00 \%$ (control). The modulus of elasticity then increased to $21822.49 \mathrm{~N} / \mathrm{mm}^{2}, 22494.24 \mathrm{~N} / \mathrm{mm}^{2}, 23182.42 \mathrm{~N} / \mathrm{mm}^{2}$ and $21438.14 \mathrm{~N} / \mathrm{mm}^{2}$ at $0.10 \%$, $0.20 \%, 0.30 \%$ and $0.40 \%$ respectively. This increase was as a result of the polythene fibre which helps to stabilize the micro cracks and increase the strength thereby reducing the porosity of the cement paste as well as increases the strength[26]. This increase was noticed up to $0.40 \%$ fibre addition after which a sudden and drastic drop of modulus of elasticity was again observed. This sudden decrease was as a result of loss in cement/aggregate matrix which in turn alters the energy absorption properties of the polythene fibre significantly[26].Consequently, for protection of the beam against excessive deflection, the fibre content should not exceed $0.3 \%$, where the modulus of elasticity of the beams was increased by about $4.0 \%$. Based on the results obtained it can be concluded that if the parameter of interest of flexural strength is to be considered, then the optimum polythene fibre content is $0.4 \%$. However if the member stiffness is of interest, then the optimum polythene fibre content should be $0.3 \%$. However, the optimum polythene fibre content can therefore be taken as not exceeding $0.4 \%$.

\section{CONCLUSION AND RECOMMENDATIONS}

\subsection{CONCLUSIONS}

1. The coarse / fine aggregate were conform to the grading requirements in accordance with the nominal size of aggregate specified (reproduced from[27].

2. Slump test was carried out to determine the workability and consistency of fresh concrete. The efficiency of all fiber reinforcement was dependent upon achievement of a uniform distribution of the fibers in the concrete, their interaction with the cement matrix, and the ability of the concrete to be successfully cast or sprayed[28].

3. The addition of Polythene fibre has a significant effect on the compressive strength, flexural strength and modulus of elasticity of reinforced concrete beams provided the percentage of fibre added do not exceed $0.4 \%$ by weight of the total components of the constituents of the beam. 
4. Increasing the percentage of polythene fibre in the concrete beyond $0.40 \%$ resulted to a decreased in the compressive strength, flexural strength and modulus of elasticity of the beam when compared to the control beam.

5. The 28 days compressive strength, flexural strength and modulus of elasticity of a polythene fibre reinforced concrete beam increased by about 3.0\% for a fibre inclusion not greater than $0.4 \%$ when compared to the control beam ( $0.00 \%$ fibre).

6. Fiber addition improves ductility of concrete and its post-cracking load-carrying capacity.

7. The addition of polythene fibre in the concrete helps to reduce the bulk density of the concrete beam when compare to the control beams.

8. Polythene fibre help to produce a lightweight concrete that in turn may resulted to a reduce dead load of the concrete structures which may help in determining the structural consideration of the structure during design.

\subsection{RECOMMENDATIONS}

1. From the experimental point of view, it is recommended that global quantity of Polythene fibre to be added to concrete mix for flexural strength, modulus elasticity and compressive strength should not exceed $0.3 \%$ by weight of the total design mix.

2. it is recommended that a machine be invested that can be used in cutting the polythene fibre to avoid errors due to measurement and energy involved when using manual cutting of the fibre.

\section{REFERENCES}

[1] Bentur A., and Mindess S., (2006) "Fibre Reinforced Cementitious Composites", Elsevier Science Publishing Ltd., New York, United State.

[2] Holt, E. and Leivo, M., (2004); "Cracking risks associated with early age shrinkage" Cement and Concrete Res. $26 \quad$ (2004) 521-530

[3] Naaman, A.E., (1985) "Fiber Reinforcement for Concrete"ACI Concrete International, 7(3): 21-25

[4] BS 8110 (1997); "Structural use of concrete, Part 1", Code of Practice for Design and Construction, British Standards Institution (BSI), London, 132.

[5] Zhang, Y.L., Li, Y., Ma, H. and Yu, T. (2013); Tensile and Interfacial Properties of Unidirectional Flax/Glass Fiber Reinforced Hybrid Composites. Composites Science and Technology, 88, 172-177.

[6] Krishna M. R., Dakhshina N.M., Santhosh V.K. (2011); ' Behaviour of Polypropylene Fibre Reinforced Fly Ash Concrete Deep Beams in Flexure and Shear'. Asian Journal of Civil Engineering (Building and Housing), 12(2):143-154.

[7] Mackay J. and Trottier J.F. (2004); "Post-crack behavior of steel and synthetic fibres under flexural creep", in Proceedings $2^{\text {nd }}$ International Conference on Engineering Developments in Shotcrete, Australia

[8] Wang, Y., Backer, S., and Li, V. C. (1987); "An experimental study of synthetic fibre reinforced cementitious composites" Journal of Materials Science, 22(12), 4281-4291.

[9] Aliyu, B. N. (2010), "An Analysis of Municipal Solid Waste in Kano Metropolis, Nigeria” Department of Geography, Kano University of Science and Technology, Wudil, Kano State, Nigeria pp. 111-119.

[10] ASTM D4791(2010), Standard Test Method for Flat Particles, Elongated Particles, or Flat and Elongated Particles in Coarse Aggregate, ASTM International, West Conshohocken, PA, 2010, www.astm.org.

[11] BS 812(1984); "Part 103, "Methods for Determination of Particle Size Distribution", British Standard Institution London.

[12] IS: 4031 (Part 4) (1988); Methods of Determination of Consistency and setting time of Standard Cement Paste (laboratory manual of concrete technology), bureau of India standards, Shivaji University Curriculum, New Delhi, India.

[13] IS: 4031 Part 3, (1988); 'Methods of Determination of Soundness of Cement by Le-Chatelier methods,' (laboratory manual of concrete technology), bureau of India standards, Shivaji University Curriculum. New Delhi, India.

[14] IS: 4031 Part 1, (1988); 'Methods of Determination of Fineness of Cement by dry sieving', laboratory manual of concrete technology, bureau of India standards, Shivaji University Curriculum, New Delhi, India.

[15] Choi, S. Y., Park, Y. H., \& Jung, W. T. (2012). "A study on the bond performance improvement of polypropylene macro fibers according to the change of surface area" Advanced Materials Research, 557, $1440-1446$ 
[16] IS; 456, (2000); "Indian code of practice for plain and reinforced concrete (fourth version).

[17] ASTM A820, (1996); Standard Specification for Steel Fibre for Fibre Reinforced Concrete America Association of Testing and Materials International n 100 Barr Harbor Drive, P.O Box C700, West Conshohocken, Pa 19428- 2959 Tel: 610-832-9500 n fax: 610-832-9555 n email: service@astm.org n website: www.astm.org.

[18] IS: 516, (1999); "'method of test for splitting tensile strength of concrete' BIS New Delhi,

[19] ASTM C78/C78M (2000); Methods of testing for Flexural Strength of Concrete (Using Simple Beam with Third Point Loading) Department of transportation Division of engineering services Transportation Laboratory 5900 Folsom Blvd. Sacramento, California 95819- 4612.

[20] Rami, H. H. Ahmed, M. A. (2001); "Role of synthetic fibers in delaying steel corrosion cracks and improving bond with concrete" Canadian Journal of Civil Engineering, no. 28, pp. 787-793.

[21] Kamran M. Nemati, K., (2015); "Progress in concrete technology", university of Washington USA.

[22] Singh, S., Shukla, A., and Brown, R. (2004); "Pullout behavior of polypropylene fibers from Cementitious matrix", Cement and Concrete Research, 34(10), 1919-192

[23] Naaman, A., Wongtanakitcharoen, T. and Hauser, G., (2005); "Influence of different fibres on plastic shrinkage cracking of concrete", ACI Mater J, Vol. 32, pp. 102-107,

[24] Buratti, N., Mazzotti, C. and Savoia, M., (2011); "Post-cracking behaviour of steel and macro- synthetic fibre-reinforced concretes Constr. Build. Mater", 25(2): 2713-2722,

[25] Rao, K. D., Kushwaha, H. S., Verma, A. K., Srividya, A.(2007); “Quantification of epistemic and aleatory uncertainties in level-1", probabilistic safety assessment studies Reliability Engineering and System Safety 92, pp. 947-956,

[26] Kamran M. Nemati, K., (2015); "Progress in concrete technology”, university of Washington USA.

[27] BS 812 (1975); Part 101, "Guide to Sampling and Testing Aggregates", British Standard Institution London.

[28] Brown J. Atkinson T., (2012); “Propex Concrete Systems (International)", United Kingdomproceedingsof FIBCON2012, ICI, Nagpur, India, February 13-14,

\section{AUTHOR'S BIOGRAPHY}

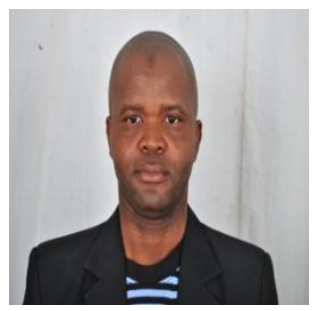

Engr. Dr. Hassan Usman Mahamud, is a Nigeria. I graduated with a bachelor degree in civil engineering, (B.Eng. Civil), Master degree in Structural Engineering, (M.Sc. struct.), and a doctorate degree in structural reliability engineering, (PhD. structural Reliability) all from Ahmadu Bello University, Zaria, Nigeria.

I am vast in both structure and infra structural (such as bridges, buildings as well as high way) design, supervision and constructions. Presently I am the project manager with a construction firm 'Inter Access Project Limited, Kano, North West Nigeria.

Among other places worked was as a Chief Resident Engineer for the supervision of the Dualisation of Kano-Maiduguri Road in the North Western and North Eastern Nigeria by the federal Republic of Nigeria. A project which covers over 200km length of road with about twelve (12) nos. of land and river bridges at various locations on the road alignment. I have also taught as a part-time and visiting lecturer in various institutions in Nigeria. I am presently residing in Kano, a state in the North western Nigeria.

Citation: U. Hassan and I. Abubakar (2018) Properties of Reinforced Concrete Beams Admixed with Polythene Fibre Polymer, International Journal of Constructive Research in Civil Engineering, 4(1), pp.113. DOI: http://dx.doi.org/10.20431/2454-8693.0401001

Copyright: () 2018 U. Hassan and I. Abubakar, This is an open-access article distributed under the terms of the Creative Commons Attribution License, which permits unrestricted use, distribution, and reproduction in any medium, provided the original author and source are credited. 